\title{
Utilização de métodos alternativos na determinação da contaminação pirogênica no controle de produtos injetáveis sujeitos à vigilância sanitária
}

\author{
Vanessa Cristina Rezende Melandri ${ }^{1}$ \\ Gizeli Costa Faria ${ }^{2}$ \\ Cristiane Caldeira ${ }^{3}$ \\ Octávio Augusto Presgrave ${ }^{4}$
}

Resumo

Todos os produtos injetáveis de uso humano devem ser livres de pirogênio. Este contaminante é considerado um grave problema de saúde pública, pois pode causar febre, podendo levar o paciente a um quadro de choque ou até a óbito. O teste de pirogênio é realizado em coelhos, principalmente no controle de soros, dos problemas éticos e do alto custo na utilização de animais, o teste em vacinas e hemoderivados, embora ensaios de LAL e MAT sejam considerados como alternativas para determinados produtos. O objetivo deste estudo foi realizar uma revisão da literatura sobre a evolução do teste de pirogênio e avaliar a possibilidade de aceitação regulatória de métodos alternativos pelos laboratórios oficiais, no controle de produtos injetáveis. Conclui-se que, apesar da existência de métodos alternativos, a carência de novos estudos e a limitação da aplicação desses métodos, principalmente para imunobiológicos, não permite a substituição do teste in vivo a não ser nos casos preconizados pelas Farmacopeias. Dessa forma, apesar dos problemas éticos e do alto custo na utilização de animais, o teste em coelhos continua a ser, até o momento, o teste de escolha para garantir a qualidade de grande parte dos produtos injetáveis, até que o MAT possa ser validado e reconhecido para uma ampla classe de produtos.

Palavras-chave: Pirogênio. Métodos alternativos. Produtos injetáveis. Controle da qualidade.

\footnotetext{
1 Especialização em Toxicologia Aplicada à Vigilância Sanitária.

2 Especialização em Toxicologia Aplicada à Vigilância Sanitária.

3 Mestre em Ciências, Tecnologista Sênior, DFT.

4 Mestre em Ciências, Tecnologista Sênior, DFT.
} 


\section{Introdução}

Qualquer substância que tenha a capacidade de induzir febre recebe o nome de pirogênio, do grego pyro que significa "fogo" e genesis que significa "criar ou resultar". Esses contaminantes podem se originar de diversas fontes como bactérias, vírus, fungos, materiais antigênicos e alguns medicamentos. A endotoxina, também designada como lipopolissacarídeo (LPS), proveniente de bactérias Gram-negativas, é responsável pela maior parte das contaminações e devido à natureza termoestável desse composto nem sempre é possível ser eliminada através dos processos normais de esterilização (BROOM, 2007; HARTUNG et al., 2001; BEUTLER, 2002; HOFFMANN et al., 2005a; SIQUEIRA; DANTAS, 2000).

Quando um microrganismo invade um hospedeiro e entra na corrente sanguínea, estimula leucócitos a sintetizarem e liberarem um grupo de moléculas que podem induzir febre, chamadas de citocinas. As mais importantes são: a Interleucina-1 $\beta$ (IL-1 $\beta$ ), Interleucina-6 (IL-6), Fator de Necrose Tumoral- $\alpha$ (TNF$-\alpha)$ e Interferon- $\gamma($ IFN- $\gamma$ ) sendo capazes de atuar no centro termorregulador do organismo e elevar a temperatura corporal causando febre (BRASIL, 1977; HOFFMANN et al., 2005a; SIQUEIRA; DANTAS, 2000).

A contaminação pirogênica pode ser considerada um grave problema de saúde pública, podendo levar o paciente a um quadro de choque que poderá culminar em óbito, por isso o controle da qualidade desses produtos é tão importante (BLATTEIS et al., 2000; INCQS, 2005).

Todos os produtos injetáveis de uso humano que se encontram no mercado devem ser livres de pirogênio (PRESGRAVE, 2003). O Instituto Nacional de Controle de Qualidade em Saúde, da Fundação Oswaldo Cruz (INCQS/FIOCRUZ), como o laboratório oficial da Agência Nacional de Vigilância Sanitária (ANVISA), bem como os Laboratórios Centrais de Saúde Pública (LACENs), são responsáveis pelo controle da qualidade desses produtos, seguindo o especificado em cada registro e de acordo com a PORTARIA 109/1993 (BRASIL, 1977; BRASIL, 1993; MIRANDA; HENRIQUES, 2005). 
Medicamentos e hemoderivados somente chegam para análise nos laboratórios oficiais através de denúncias ou de programas estabelecidos com secretarias municipais ou estaduais de saúde. No caso específico de soros e algumas vacinas, as análises são realizadas lote a lote, como parte do Programa Nacional de Imunização, como requisito básico para a efetivação da compra dos mesmos pela Secretaria de Vigilância em Saúde. Além desses, também sofrem análise todos os dispositivos médicos que servirão como instrumento de administração de fluídos ou soluções (BRASIL, 1993).

A legislação nacional preconiza como testes de segurança para a detecção de pirogênios o teste in vivo em coelhos e o Teste de Endotoxina Bacteriana, também conhecido como Lisado de Amebócito de Limulus (LAL). (FARMACOPEIA BRASILEIRA, 2003). Dessa forma, segundo essa regulamentação, deve ser realizado o teste em coelhos para hemoderivados (BRASIL, 2000), soros hiperimunes e algumas vacinas (FARMACOPEIA BRASILEIRA, 2003) sendo que, somente nos casos de parenterais de grande volume, é facultado o uso de testes em animais ou o LAL (BRASIL, 1997; FREITAS, 2008).

Baseando-se no Princípio dos 3Rs (Replacement, Reduction and Refinement - Substituição, Redução e Refinamento) alguns métodos foram desenvolvidos a partir do mecanismo da febre e quantificação de citocinas em linhagens celulares e sangue total humano. Recentemente, esses testes foram incorporados à Farmacopeia Europeia denominados coletivamente de Teste de Ativação de Monócitos, MAT (Monocyte Activation Test) (ICCVAM, 2008; EUROPEAN PHARMACOPEIA, 2006). O objetivo desse trabalho foi revisar a literatura sobre a evolução do teste de pirogênio, analisando criticamente a aplicabilidade dos métodos existentes, e avaliar a possibilidade de aceitação regulatória de métodos alternativos pelos laboratórios oficiais, no controle de produtos injetáveis sujeitos à Vigilância Sanitária.

\section{Teste de Pirogênio In Vivo}

O ensaio de pirogênio em coelhos foi descrito por Hort e Penfold em 1912. $\mathrm{Na}$ metade dos anos 20, Seibert concluiu que as reações febris causadas por injetáveis estavam relacionadas com produtos termoestáveis, de origem bacteriana. $\mathrm{Na}$ 
década de 40, Co Tui demonstrou que coelhos respondem melhor à ausência de pirogênios enquanto que cães são melhores indicadores da presença de pirogênios (PEARSON, 1985).

O Comitê de Revisão da Farmacopeia Americana autorizou em 1941 o Subcomitê 3 em Ensaios Biológicos a iniciar o primeiro estudo colaborativo para o Ensaio de Pirogênio sob a direção de Henry Welch. Os resultados desses estudos foram publicados em 1943. Ainda durante o desenvolvimento desse estudo, o primeiro método oficial para detecção de pirogênio foi incorporado à décima segunda edição da Farmacopeia Americana no ano de 1942 sendo utilizado na sua forma original até recentemente (WILLIAMS, 2007; KIKKERT et al., 2008).

Apenas em 2001, a Farmacopeia Americana (UNITED STATES PHARMACOPEIA, 2000), modificou os critérios de avaliação do teste, tornando-os mais rigorosos, considerando como febre a variação individual de temperatura (VIT) igual ou superior a $0,5^{\circ} \mathrm{C}$, substituindo o critério anterior de igual ou superior a $0,6^{\circ} \mathrm{C}$. Em 2003, a Farmacopeia Brasileira mudou também o seu critério no fascículo $5^{\circ}$ da $4^{\text {a }}$ edição (FARMACOPEIA BRASILEIRA, 2003).

O teste de pirogênio in vivo fundamenta-se na observação da resposta febril em coelhos, após injeção intravenosa da solução em análise, na qual se mede a temperatura retal dos animais a intervalos de 30 minutos, por um período de 3 horas. Um primeiro teste é realizado com três animais e, caso o resultado seja duvidoso, cinco novos coelhos são testados para se ter o resultado final. No primeiro caso, se nenhum coelho apresentar um aumento individual de temperatura de 0,5 ${ }^{\circ} \mathrm{C}$ ou mais, acima da respectiva temperatura de controle, o produto atende aos requisitos para ausência de pirogênio. Na repetição, se no máximo três dos oito coelhos mostrarem aumentos individuais de temperatura de $0,5^{\circ} \mathrm{C}$ ou mais, e se a soma dos oito aumentos máximos individuais não exceder $3,3^{\circ} \mathrm{C}$, o produto atende aos requisitos para ausência de pirogênio (WILLIAMS, 2007). Cabe ressaltar que coelhos apresentam o mesmo limiar de endotoxina que causa febre no homem, ou seja, 1 ng/kg ou 5 UE/kg (HOCHSTEIN, 1990). 


\section{Métodos alternativos}

No século XIX, Jeremy Bentham demonstrou seu interesse em proteger os animais com a seguinte reflexão: "a questão não é se os animais raciocinam ou se eles podem falar, mas se eles sofrem.” Ainda no mesmo século, Marshall Hall propôs o primeiro código de ética na experimentação animal, que sugeria a substituição de grandes animais por animais inferiores na escala zoológica, a redução de repetições desnecessárias de ensaios com animais e a preocupação com a diminuição da dor imposta aos animais. No ano de 1842, foi inaugurada a primeira sociedade protetora dos animais, a "British Society for the Prevention of Cruelty to Animals", posteriormente denominada "Royal Society for the Prevention of Cruelty to Animals" (PRESGRAVE, 2003).

A partir de 1959, com a publicação do livro "The principles of humane experimental technique" foi introduzido o conceito dos 3Rs (reduction, refinement and replacement) no meio científico que consiste na redução do número de animais, refinamento das técnicas experimentais, minimizando o sofrimento do animal e preservando o seu bem estar e, quando possível, a substituição dos testes realizados in vivo por testes in vitro. Esse conceito evoluiu como uma tendência mundial, iniciando uma forte pressão com implicações éticas quanto a não utilização de animais em pesquisas científicas e a mobilização de várias entidades e órgãos regulatórios no árduo trabalho da validação de métodos alternativos na área de toxicologia (RUSSEL; BURCH, 1959; BALLS et al., 1995).

Desde a década de 60, um grande esforço vem sendo realizado na busca por métodos alternativos ao teste de pirogênio in vivo. Em 1964, Levin e Bang verificaram que preparações de endotoxina termoestáveis isoladas de Escherichia coli e um Vibrio marinho induziam a coagulação extracelular da hemolinfa (sangue) do caranguejo-ferradura (Limulus poliphemus) (PEARSON, 1985). Posteriormente, Levin e colaboradores desenvolveram um ensaio sensível para endotoxina em plasma humano usando material lisado dos amebócitos de endotoxina. Como método de detecção de endotoxinas bacterianas, o ensaio de LAL foi pela primeira vez introduzido na Farmacopeia Americana em 1980. No Brasil, foi incluído na 4a edição da Farmacopeia em 1996 (PINTO et al., 2003). 
Apesar de incontestavelmente apropriado para determinados produtos, como radiofármacos, sua ineficiência em detectar outros tipos de pirogênios que não sejam de origem Gram-negativa, impede uma completa substituição do teste de pirogênio em coelhos (HARTUNG et al., 2001; POOLE et al., 2002; HOFFMANN et al., 2005b). Outro problema reside na capacidade da endotoxina de se ligar às proteínas plasmáticas e não ser normalmente detectada no LAL, já que este somente quantifica endotoxina livre limitando o seu uso para determinados produtos principalmente imunobiológicos (PARK et al., 2005; SCHINDLER et al., 2009). Segundo Brandenburg e colaboradores (2009), há sérias restrições em relação à utilização do LAL na terapia antibacteriana. Segundo os autores, alguns ensaios clínicos, como a presença de bacteremia, não foram correlacionados ao LAL em casos de contaminação por bacterias Gram-negativas. Também se constatou que a atividade do LAL não apresentou correlação com a expressão das citocinas (TNF- $\alpha$, IL-1 $\beta$ e Il-6) em células mononucleares.

Existem diversos métodos de LAL, entretanto, os mais utilizados são o de gelificação e cromogênico. No primeiro caso, volumes iguais do reagente LAL e da solução a ser analisada são homogeneizados e incubados em banho-maria a $37^{\circ} \mathrm{C}$ por uma hora (FUKUMORI, 2008). A presença do gel que se mantém sólido durante a inversão é considerada positiva para endotoxinas. Nesse método, obtém-se, somente, uma medida semiquantitativa, uma vez que o resultado é expresso em faixas (PRESGRAVE, 2003).

No LAL cromogênico, um substrato cromóforo é incorporado ao complexo endotoxina-LAL resultando em reação de cor, diretamente proporcional à quantidade de endotoxina (FUKUMORI, 2008). Esse método permite uma quantificação precisa da quantidade de endotoxina presente na solução testada. Existem outros métodos descritos na Farmacopeia que também proporcionam informações acerca da concentração de endotoxina nas amostras, entre eles, turbimétrico quantitativo, colorimétrico de proteína e nefelométrico (WILLIAMS, 2007; FUKUMORI, 2008).

Seguindo a tendência mundial na busca por métodos alternativos ao uso de animais, o teste de liberação de citocinas, utilizando linhagens celulares ou sangue humano foi desenvolvido no final da década de 1980 e início dos anos 1990, toman- 
do por base o princípio do mecanismo da febre, quantificando mediadores inflamatórios (IL-1 $\beta$, IL-6, TNF- $\alpha$ ) envolvidos neste processo (POOLE et al., 1988; HARTUNG; WENDEL, 1995; HARTUNG; WENDEL, 1996; NETEA et al., 2000; HARTUNG, 2001; SCHINDLER et al., 2004, CALDEIRA, 2005; PRESGRAVE, 2009a).

A primeira demonstração da aplicação da liberação de citocinas in vitro foi através do "teste do monócito", em comparação com os ensaios em coelho e LAL. Nesse método, uma linhagem celular monocítica humana denominada MONOMAC-6 (MM6) foi submetida à presença de endotoxinas de diversas origens e as citocinas (IL-1 e TNF) foram dosadas demonstrando uma boa relação dose-resposta (POOLE et al., 1988; ZIEGLER-HEITBROCK et al., 1988).

A partir dessa publicação, alguns outros trabalhos foram desenvolvidos no sentido de melhor estudar a liberação de citocinas em diferentes cultivos de monócitos e sua relação com os ensaios em coelhos e LAL (PRESGRAVE, 2003).

A utilização de células mononucleares isoladas de sangue periférico (PBMC) foi demonstrada por Hansen e Christensen (1990), como um indicador sensível de contaminação por endotoxina. Resultados promissores indicaram que, além de sensível, o método com PBMC para IL-1, era capaz de detectar endotoxinas e bactérias Gram positivas (S. aureus) sendo considerado como um modelo substitutivo quando comparado ao LAL e o teste in vivo. Posteriormente, outro estudo concluiu que a liberação de IL-6 a partir de PBMC em soluções de hemoglobina também era um modelo sensível quando comparado ao teste in vivo. (HANSEN; CHRISTENSEN, 1990).

Em 1991, Taktak e colaboradores apresentaram um estudo que resume o desenvolvimento de um teste de pirogênio in vitro baseado na liberação de IL-6 a partir da linhagem celular Mono Mac 6. Os autores sugerem que o método MM6/ IL-6 representa uma alternativa importante e pode ser uma forma mais adequada para testar a contaminação do produto final em produtos parenterais, como a albumina de soro humano (HSA), que não pode ser detectado no LAL e no teste in vivo nas condições experimentais avaliadas (ICVAM, 2008). 
Em outro estudo, Hartung e Wendel (1996) concluíram que, após estimulação do sangue total (WB) com endotoxina, bactérias Gram-positivas (S. aureus) ou componentes desses organismos (muropeptidios, LTA, enterotoxinas e estreptolisina $\mathrm{O}$ ) liberavam IL-1 $\beta$ de forma dependente à concentração do estímulo. Com base nesses resultados, os autores sugeriram a utilização do método de ensaio WB/ IL-1 $\beta$ como uma alternativa para o teste in vivo (ICVAM, 2008).

Eperon e colaboradores desenvolveram um sistema de teste in vitro para a medição de substâncias pirogênicas usando dois subclones derivados de células MM6 (MM6-2H8 e MM6-4B5) e um de uma linhagem celular THP-1 (THP-1G3). Esses clones são relatados por serem fenotipicamente mais estáveis ao longo do tempo em relação à sua capacidade de resposta à endotoxina que as linhagens de origem. Os autores sugerem que esses métodos baseados em clones de células monocíticas in vitro são alternativas válidas para a detecção de endotoxina em preparações comerciais e produzem resultados comparáveis ao LAL e o teste in vivo. (EPERON et al., 1996; EPERON et al., 1997). Ainda na década de 90, novos estudos surgiram, como o desenvolvido por Moesby e colaboradores, $\mathrm{n}$ os quais os autores sugerem que o teste utilizando células MM6 seria um complemento útil para o LAL para a detecção de microrganismos Gram-negativos e bactérias gram-positivas (MOESBY et al., 1999; ICVAM, 2008).

Em 2001, Hartung e colaboradores apresentaram um relatório de um workshop, patrocinado pelo Centro Europeu de Validação de Métodos Alternativos (ECVAM), para examinar a situação dos testes de pirogenicidade, rever as capacidades dos novos testes e apresentar recomendações para o seu desenvolvimento. A necessidade de alternativas ao teste em coelhos foi discutida, e suas respectivas limitações foram destacadas. O workshop comparou a utilidade dos diversos métodos para testar uma variedade de materiais pirogênicos. As conclusões do workshop indicaram a necessidade de métodos de ensaio alternativos para enfrentar as limitações do teste pirogênio in vivo, mas destacou a necessidade de validação adequada de qualquer novo método.

A partir de então, novos trabalhos foram publicados com destaque para o desenvolvido por Nakagawa e colaboradores (2002) que descreveram um sis- 
tema baseado na liberação de citocinas a partir de um subclone de células MM6 (MM6-CA8) e compararam essa resposta ao sangue total e ao teste em coelhos. Os autores sugerem que as células MM6-CA8 são capazes de detectar uma variedade de pirogênios usando IL-6 como marcador, e que essas respostas são altamente relevantes para a previsão das reações em humanos.

Andrade et. al. (2003) avaliaram a utilização de PBMCs humanos e WB diluído quando comparados ao LAL e ao teste em coelhos para produtos farmacêuticos e biológicos. Os autores concluíram que ambos os métodos de PBMC e WB foram comparáveis ao LAL e ao Teste in vivo na sua capacidade de detectar e quantificar a presença de endotoxina. Além disso, o método de teste WB foi capaz de detectar IL-6 independente da concentração de endotoxina e dos outros pirogênios. Ainda em 2003, Poole e colaboradores descreveram um rápido e único teste in vitro para a presença de substâncias pirogênicas baseada na ativação de monócitos (MM6) e liberação de IL-6 (ICVAM, 2008).

Entretanto, devido à necessidade de superar algumas limitações relacionadas ao uso do sangue fresco, Schindler e colaboradores (2004) apresentaram um método de criopreservação no qual o sangue poderia ser usado imediatamente após o descongelamento, sem etapas de lavagem. A criopreservação torna o ensaio mais seguro em relação às questões de biossegurança, já que possibilita em tempo hábil testar possíveis contaminações de agentes infecciosos consequentemente aumentando a confiabilidade da resposta dos monócitos, além de facilitar o transporte e armazenamento das amostras (SCHINDLER et al., 2004)

Hoffmann e colaboradores (2005b) publicaram um estudo de validação usando 13 drogas e seis testes in vitro realizados em dez laboratórios. Os testes validados foram: PBMC/IL-6; WB/IL-1 $\beta$, WB/IL-6, MM6 IL-6, THP-Neo/TNFa e THP/TNFa. Comparado com o teste em coelhos, os novos testes são mais sensíveis, bem como de menor custo e prazo. Em contraste com LAL, todos os testes foram capazes de detectar pirogênios de origem Gram-positiva.

O processo de validação mostrou que pelo menos quatro dos seis testes, com exceção da linhagem THP, atendem aos critérios de qualidade para detecção 
de pirogênio. Segundo os autores, os resultados sugerem que a experimentação animal pode ser totalmente substituída por esses testes in vitro, destacando seu potencial na segurança e controle da qualidade de produtos injetáveis. O processo de validação formal, ou seja, a avaliação da confiabilidade e da relevância desses métodos foi desenvolvida pelo Centro Europeu de Validação de Métodos Alternativos, ECVAM (European Centre for the Validation of Alternative Methods) e possui aceite internacional (HOFFMANN et al., 2005b).

Após o processo de validação do sangue fresco em 2005, o uso do teste para sangue criopreservado foi validado por meio de um método simples de congelamento do sangue humano para a dosagem de IL-1 (SCHINDLER et al., 2006). Nesse processo, o sangue fresco é misturado a uma solução contendo DMSO e Tampão Sörensen e congelado a uma temperatura de $-70^{\circ} \mathrm{C}$ (SCHINDLER et al., 2006; PRESGRAVE et al., 2007; SPREITZER et al., 2002; DANESHIAN, 2009; HALDER, 2009; MONTAG et al., 2009; SCHINDLER et al., 2009; SILVA et al., 2009).

Em 2005, Kindinger e colaboradores apresentaram uma adaptação do MAT para avaliação do potencial inflamatório de contaminantes em amostras do ar ambiente de áreas potencialmente contaminadas como criação de animais (estábulos e chiqueiros). Recentemente, dois estudos, Liebers e colaboradores (2009) e Bernasconi e colaboradores (2010), também utilizaram a liberação de citocinas no sangue total para avaliar a atividade pirogênica em bioaerossóis e poeira de ambientes ocupacionais e não ocupacionais como edifícios públicos. Apesar dos resultados promissores, os autores deixam clara a necessidade de novos estudos contemplando outros ambientes como instituições de saúde e a necessidade do estabelecimento de valores de referência (KINDIGER et al., 2005).

Schindler e colaboradores (2009) apresentaram novos campos que o MAT tem sido aplicado, como na avaliação da contaminação de células utilizadas na terapêutica celular., a partir da observação de que os monócitos são as primeiras células a chegarem a um local de implante de placas metálicas e ligas de titânio utilizadas em próteses ortopédicas. O teste também tem sido utilizado em estudos de biocompatibilidade devido à sua preferência específica para superfícies rugosas e hidrofóbicas. 
Estudos recentes também demonstraram a alta sensibilidade do teste in vitro com sangue humano na dosagem de IL-1 $\beta$ em soluções de diálise e componentes (DANESHIAN et al., 2009). Em outro estudo recente, a liberação de IL-6 e TNFa do sangue total humano e de PBMCs foram utilizados para estimar a atividade do LPS purificado e das vesículas de membrana externa, que são empregadas como antígeno para a produção da vacina de diferentes cepas de Neisseria meningitidis do grupo B. Os autores destacaram alta sensibilidade do sangue total em relação ao LAL, e a relevância do uso de sistemas humanos para predizer a toxicidade sugerindo que esse ensaio pode ser promissor para a avaliação de segurança de vacinas (STODDARD et al., 2010).

O ECVAM apresentou ao Comitê Organizador Interagências, para Validação de Métodos Alternativos, o ICCVAM (Interagency Coordinating Committee on the Validation of Alternative Methods), a avaliação do status de validação de cinco métodos alternativos in vitro (ICCVAM, 2008; SCHINDLER et al., 2009). Os métodos avaliados foram: Sangue total humano (WB)/Interleucina IL-1 $\beta$; Sangue total humano WB/IL-1 $\beta$ : com aplicação do sangue criopreservado, Sangue total humano WB/Interleucina (IL)-6, células Mononucleares do sangue periférico (PBMC)/IL-6 e a linhagem celular Mono Mac 6 (MM6)/IL-6 (ICCVAM, 2008).

O ICCVAM recomendou que, embora nenhum desses métodos possa ser considerado um substituto completo para o teste in vivo, podem ser utilizados para detectar endotoxinas. Além disso, permite o seu uso para cada produto específico desde que fique demonstrada a equivalência ao teste in vivo em conformidade com a regulamentação aplicável (ICCVAM, 2008, SCHINDLER et al., 2009). Seguindo essas recomendações, o MAT foi incorporado à Farmacopeia Europeia (ICCVAM, 2008, EUROPEAN PHARMACOPEIA, 2006).

Devido às limitações do LAL e às recomendações em relação ao uso do MAT, a redução do número de animais no teste de pirogênio in vivo pode ser uma alternativa para contornar o grande número de coelhos utilizados.

Estima-se que, no mundo, que um grande número de coelhos seja utilizado para todos os fins de investigação e análise e, embora o número de animais usados especificamente para o teste in vivo não tenha sido relatado, é provável que esse 
número seja significativamente alto, incluindo dados reportados no Canadá e no Reino Unido (ICCVAM, 2008). Segundo dados do relatório do ICCVAM (2008), em 2002, um total de 243.838 mil coelhos foram utilizados nos Estados Unidos para todos os fins de investigação e análise. O mesmo relatório aponta que, em 2005, cerca de 313.000 coelhos foram utilizados na União Europeia (UE), sendo que, desses, cerca de 276.000 animais foram utilizados para produtos farmacêuticos e dispositivos médicos (investigação e desenvolvimento, produção e controle de qualidade, ou outras avaliações toxicológicas e de segurança).

No Brasil, dos laboratórios oficiais, somente o Instituto Octavio Magalhães (IOM), o Instituto Adolfo Lutz (IAL) e o Instituto Nacional de Controle da Qualidade em Saúde (INCQS) realizam teste de pirogênio. Este último utiliza, anualmente, cerca de 1.200 coelhos nos ensaios de pirogênio para a análise em soros, vacinas, hemoderivados, dispositivos médicos e parenterais de grande volume.

As Farmacopeias preconizam, como forma de redução, a reutilização de animais para o teste de pirogênio in vivo. Dessa forma, quando um ensaio é considerado negativo, os animais podem ser reutilizados, respeitando interstício de 48 horas. No caso de teste positivo, deve-se obedecer a um intervalo de 14 dias para que eles tornem a ser usados em novo ensaio (UNITED STATES PHARMACOPEIA, 2000; EUROPEAN PHARMACOPEIA, 2006).

A Farmacopeia Brasileira, na sua última edição, não recomenda a reutilização de coelhos para produtos biológicos devido à falta de estudos anteriores, porém mantém as condições de reutilização de animais para os demais produtos (FARMACOPEIA BRASILEIRA, 2003; SCHINDLER et al., 2009).

Apesar da carência de trabalhos científicos nessa área, foram encontrados alguns estudos com modelos de redução de animais através da reutilização de coelhos para o teste de Pirogênio in vivo. O primeiro, apresentado durante a "Primeira Oficina de Ensaios Biológicos" em Cuba, onde foi comprovada a possibilidade de reutilização dos animais para a vacina anti-hepatite B até três ou quatro vezes em um período de uma semana, reduzindo em até um terço o número de animais (BOURG, 1997). Recentemente, outro estudo utilizando o modelo de redução foi 
efetuado no Instituto Nacional de Controle de Qualidade em saúde (INCQS/FIOCRUZ), demonstrando que coelhos administrados com soros hiperimunes (Antibotrópico, Antirrábico e Anticrotálico), uma vez que se tenha obtido resultados negativos, podem ser reutilizados até quatro vezes no período de uma semana. Esse fato proporciona uma redução de até $70 \%$ no número de animais utilizados, bem como no custo do ensaio (FREITAS, 2008).

\section{Comparação entre os Métodos In Vivo e In Vitro}

O teste de pirogênio in vivo é considerado um ensaio seguro por detectar um amplo espectro de substâncias e ser aplicável a um grande número de produtos embora alguns medicamentos não possam ser avaliados por esse teste. Um importante fato reside na relação dose-resposta similar entre o homem e coelho, demonstrando que $1 \mathrm{ng} / \mathrm{kg}$ ( $5 \mathrm{UE} / \mathrm{kg}$ ) é a dose mínima que causa febre (HOCHSTEIN et al., 1990). Entretanto, é susceptível à interferência de fatores relacionados ao ambiente externo como temperatura, ruídos, umidade e ventilação. Fatores relacionados ao animal como diferenças de resposta entre raças, sexo e a variabilidade biológica também contribuem para possíveis resultados falso-positivos e falso-negativos. Outro aspecto a ser considerado é o controle da qualidade dos animais desde o seu fornecimento (WILLIAMS, 2007). Dessa forma, além de realizar os controles sanitários, genéticos e físico-químicos do ambiente, que podem reduzir ou eliminar esses interferentes, é imprescindível inserir no controle da qualidade do ensaio um instrumento que garanta a sensibilidade do animal. Um exemplo é a realização de uma curva dose-resposta frente a um estímulo pirogênico a partir de um padrão internacional (HARTUNG et al., 2001; FREITAS, 2008).

Os sistemas in vitro possuem várias vantagens em relação ao teste in vivo por serem de baixo custo, quando se leva em consideração o gasto gerado na criação e manutenção de animais de laboratório (HARTUNG et al., 2001; HOFFMANN et al., 2005). Além disso, são rápidos e de fácil execução, significando um maior número de amostras analisadas em menor tempo (Tabela 1). Esses testes possuem uma relação dose-resposta sendo quantitativos e mais sensíveis detectando endotoxinas na faixa de picogramas por mililitro independente da monografia de cada 
Tabela 1: Comparação entre os diferentes métodos in vivo e in vitro utilizados para a detecção de pirogênios.

\begin{tabular}{|c|c|c|c|}
\hline \multicolumn{4}{|l|}{ TESTES } \\
\hline & COELHO & $\mathrm{LAL}$ & MAT \\
\hline \multicolumn{4}{|l|}{ PRINCÍPIO } \\
\hline & $\begin{array}{l}\text { Mecanismo da } \\
\text { febre }\end{array}$ & $\begin{array}{l}\text { Defesa do } \\
\text { artrópodo }\end{array}$ & Mecanismo da febre \\
\hline \multicolumn{4}{|l|}{ AGENTES } \\
\hline $\begin{array}{l}\text { Bactéria Gram+- } \\
\text { Bactéria Gram - } \\
\text { Fungos } \\
\text { Vírus }\end{array}$ & $\begin{array}{l}\text { Sim } \\
\text { Sim } \\
\text { Sim } \\
\text { Sim }\end{array}$ & $\begin{array}{l}\text { Não } \\
\text { Não } \\
\text { Não } \\
\text { Não }\end{array}$ & $\begin{array}{l}\text { Sim } \\
\text { Sim } \\
\text { Sim } \\
\text { Sim }\end{array}$ \\
\hline \multicolumn{4}{|l|}{ AMOSTRAS } \\
\hline $\begin{array}{l}\text { Medicamentos } \\
\text { Dispositivos } \\
\text { Médicos } \\
\text { Produtos } \\
\text { Biológicos } \\
\text { Ar e poeira } \\
\end{array}$ & $\begin{array}{l}\text { Parcialmente }{ }^{(1)} \\
\text { Sim } \\
\text { Sim } \\
\text { Não }\end{array}$ & $\begin{array}{l}\text { Sim } \\
\text { Sim } \\
\text { Parcialmente } \\
\text { Parcialmente }^{(3)}\end{array}$ & $\begin{array}{l}\text { Sim } \\
\text { Sim } \\
\text { Sim } \\
\text { Sim }\end{array}$ \\
\hline \multicolumn{4}{|l|}{ VANTAGENS } \\
\hline & $\begin{array}{l}\text { Detecta vários } \\
\text { tipos de } \\
\text { pirogênios }\end{array}$ & $\begin{array}{l}\text { Rápido } \\
\text { Fácil execução } \\
\text { Baixa infra- } \\
\text { estrutura } \\
\text { Baixo custo } \\
\text { Redução de custos } \\
\text { e prazo de análises }\end{array}$ & $\begin{array}{l}\text { Rápido } \\
\text { Fácil execução } \\
\text { Baixa infra-estrutura } \\
\text { Baixo custo } \\
\text { Redução de custos e } \\
\text { prazo de análises } \\
\text { Detecta vários tipos de } \\
\text { pirogênios } \\
\text { Aplicável a todos os } \\
\text { produtos }\end{array}$ \\
\hline \multicolumn{4}{|c|}{ DESVANTAGENS } \\
\hline & $\begin{array}{l}\text { Variabilidade } \\
\text { biológica } \\
\text { Não aplicável a } \\
\text { todos os produtos } \\
\text { Alto custo de } \\
\text { manutenção de } \\
\text { animais } \\
\text { Questões éticas }\end{array}$ & \begin{tabular}{|l} 
Só detecta origem \\
Gram - \\
Não aplicável a \\
alguns produtos \\
biológicos
\end{tabular} & $\begin{array}{l}\text { Necessidade de } \\
\text { validação para produtos } \\
\text { não contemplados } \\
\text { na publicação da } \\
\text { Farmacopéia }\end{array}$ \\
\hline
\end{tabular}

(1) Exceto medicamentos que interfiram diretamente no mecanismo da febre (p. ex.: analgésicos, anti-inflamatórios etc.); (2) Produtos biológicos contendo proteínas plasmáticas podem interferir no resultado do LAL; (3) Exceto amostras sólidas. Além disso, outros contaminantes (fungos, ácaros etc) mascaram o resultado no LAL. 
produto. O uso do MAT em relação ao LAL possui a vantagem em detectar um amplo espectro de pirogênios e ser aplicável a produtos biológicos e amostras ambientais como ar e poeira (KINDINGER et al., 2005; SCHINDLER et al., 2009). Além disso, é baseado no mesmo princípio do teste in vivo, ou seja, no mecanismo da febre, facilitando possíveis correlações in vivo e in vitro (HOFFMANN et al., 2001). A desvantagem do uso do sangue fresco no MAT foi contornada com o processo de criopreservação, tornando o ensaio mais seguro e de fácil execução (HOFFMANN et al., 2005; SCHINDLER et al., 2006; ICCVAM, 2008; SCHINDLER et al., 2009).

\section{Discussão}

Os testes de pirogenicidade são usados principalmente por parte das autoridades reguladoras para o produto final de uso humano como medicamentos parenterais, produtos biológicos e dispositivos médicos. Os resultados desses ensaios são utilizados para limitar, a um nível aceitável, os riscos de reação febril em pacientes expostos ao produto de interesse (ICCVAM, 2008; UNITED STATES PHARMACOPEIA, 2000; FARMACOPEIA BRASILEIRA, 2003; EUROPEAN PHARMACOPEIA, 2006).

Apesar de amplamente aceito, por ser capaz de detectar vários tipos de pirogênios e ser aplicável a diversos produtos, o método in vivo ainda é bastante questionável em vários pontos. Um aspecto importante é a necessidade de extrapolação entre as espécies de coelhos para os seres humanos apesar do limiar de febre semelhante entre humanos e coelhos. As questões éticas envolvendo o uso de animais em experimentação também pode ser alvo de críticas tendo em vista a variabilidade biológica dos animais e as interferências que podem levar a uma resposta falso-positiva ou falso-negativa. Como exemplo, podemos citar a elevação de temperatura por estresse causado por um ruído na sala de experimentação, as diferenças de resposta entre raças de coelhos e a influência de fatores ligados ao sexo. A postura que o animal adota na gaiola de contenção, entre outros fatores, pode resultar numa resposta negativa, sem contar com fatores ambientais que devem ser bem controlados (HARTUNG et al., 2001; PRESGRAVE, 2003; WILLIAMS, 2007). 
Determinadas drogas também podem influenciar na resposta dos animais aumentando, diminuindo ou cessando a resposta febril. Um exemplo de substâncias que cessam a febre são acetanilida, acetofenetidim, o ácido acetilsalicílico (AAS) e antitérmicos como paracetamol e dipirona. Drogas que mascaram e diminuem a febre são os derivados de fenotiazina, hipnóticos, anestésicos locais (procaína) e estrofantim. Algumas substâncias como esteroides e antibióticos podem provocar febre em mamíferos. Portanto, é extremamente importante entender o efeito farmacológico das soluções testadas antes de submeter a amostra ao teste de pirogênio em coelhos (WILLIAMS, 2007).

O LAL é apropriado na substituição do teste de pirogênio para determinados produtos, como água para injeção e medicamentos que não podem ser aplicados em animais (INCQS, 2005). Possui a vantagem de utilizar hemolinfa de animal invertebrado, além de avaliar a contaminação frente a um padrão de endotoxina que permite uma medição semiquantitativa, no caso do método de gelificação ou quantitativa, quando se trata do LAL cromogênico. Essa diferença ocorre, uma vez que o teste de gelificação apresenta como resultado uma faixa informando a concentração de endotoxina. No caso do LAL cromogênico, a concentração é obtida através da interpolação de valores que se encontram dentro da curva, construída com diversas concentrações do padrão e analisada por regressão e correlação lineares.

A limitação do uso do LAL em relação à sua ineficiência em detectar outros tipos de pirogênios que não sejam de origem Gram-negativa impede uma completa substituição do teste de pirogênio em coelhos (HUSZÁR et al., 2002; PARK et al., 2005; SCHINDLER et al., 2004; SCHINDLER, 2009). Outra limitação é em relação às interferências de produtos biológicos, tais como soros hiperimunes, vacinas, hemoderivados e amostras ambientais sólidas (SCHINDLER, 2009). Existem poucos trabalhos relacionando o LAL e a detecção de endotoxinas nesses produtos. Alguns artifícios são descritos na literatura buscando minimizar os efeitos no teste dos interferentes ou inibidores presentes (SILVEIRA et al., 2004; REINHARDT, 2008).

Um dos principais problemas descritos reside na capacidade da endotoxina de se ligar a proteínas plasmáticas e não ser detectada no LAL já que este só quantifica endotoxina livre. Segundo Park e colaboradores (2005), no caso de va- 
cinas como a Hepatite $B$, além dos componentes proteicos, existe a interferência do hidróxido de alumínio $\left(\mathrm{Al}(\mathrm{OH})_{3}\right)$ no teste (PARK et al., 2005). Neste estudo foi comparado o LAL cromogênico e gelificação ao Teste in vivo e após várias diluições da amostra e processos de filtração para a retirada do $\mathrm{Al}(\mathrm{OH})_{3}$ foi possível detectar apenas a endotoxina pelo teste de gelificação, sugerindo apenas neste caso o LAL como alternativa ao coelho (SILVEIRA et al., 2004).

No caso de soros hiperimunes não há trabalhos publicados nesse sentido, ratificando a importância do teste in vivo para esses produtos. A mesma situação pode ser estendida para os hemoderivados. Estudos com imunoglobulinas mostraram que o LAL por gelificação pode ser aplicado apenas quando utilizado com inibidor apropriado (SILVEIRA et al., 2004).

Cabe ressaltar que, com a validação e inclusão do LAL nas farmacopeias como uma alternativa ao uso do teste de pirogênio em coelhos, houve uma redução de aproximadamente $80 \%$ dos testes in vivo. Além disso, essa inclusão permite que o LAL, assim como o teste em coelhos, também possa ser usado como referência para estabelecer uma correlação, no processo de validação de novos ensaios in vitro (SCHINDLER et al., 2004).

Devido às recomendações e limitações do teste em coelhos e do LAL, foi desenvolvido um novo método baseado na ativação in vitro de células monocíticas humanas em resposta a pirogênios. Esse método surgiu como uma proposta de substituição ao teste in vivo e combina a sensibilidade do LAL com o grande espectro de substâncias detectáveis pelo teste em coelhos. Além disso, o novo método, por utilizar células de origem humana, reflete melhor a resposta fisiológica possibilitando uma melhor compreensão dos mecanismos biológicos responsáveis pela reação de febre em humanos (POOLE et al., 1988; HANSEN; CHRISTENSEN, 1990; TAKTAK et al., 1991; HARTUNG; WENDEL, 1996, EPERON et al., 1996; EPERON et al., 1997; MOESBY et al., 1999; HARTUNG, 2001, NAKAGAWA et al., 2002; ANDRADE et al., 2003, SCHINDLER et al., 2004).

Os testes de ativação de monócitos também apresentam outras vantagens em relação aos empregados atualmente, como a redução de custos e prazo de aná- 
lises, principalmente com o uso do sangue criopreservado. Entretanto, um estudo recente mostrou que pode existir diferença significativa entre a utilização do sangue fresco e criopreservado em relação aos níveis de expressão do gene de TNF- $\alpha$ após estimulação com LPS. Segundo os autores, a diminuição da viabilidade celular devido à criopreservação e à depleção dos níveis de citocinas podem ser atribuidos à baixa expressão de TNF- $\alpha$ no sangue congelado. Os resultados sugerem fortemente que o sangue total fresco é a melhor escolha para estudos de estimulação in vitro na determinação de mediadores inflamatórios (CHEN et al., 2010).

Apesar do esforço da comunidade científica e o grande número de publicações, o MAT foi regulamentado pela Farmacopeia Européia apenas como um terceiro teste, sem substituir os já existentes. Alguns pontos críticos podem ser destacados, principalmente pelo fato de o processo de validação demonstrar apenas a capacidade de detecção para endotoxina. Os dados apresentados na literatura, segundo o próprio relatório do ICCVAM, são insuficientes para comprovar a capacidade em detectar pirogênios que não sejam de origem Gram-negativa e sua utilização para produtos biológicos. Além disso, os métodos validados não foram adequadamente avaliados na sua capacidade em detectar endotoxinas quando comparados ao LAL e ao Teste in vivo, dificultando sua utilização como um substituto completo ao testes já existentes (HARTUNG; WENDEL, 1996; HOFFMANN et al., 2005a; NAKAGAWA et al., 2002; SCHINDLER et al., 2006; ICCVAM, 2008; SCHINDLER, 2009).

No que tange à reutilização de animais, a Lei 11.794/2008, que regulamenta a utilização de animais na experimentação e ensino no Brasil, através do seu Artigo 14 , parágrafo $8^{\circ}$, preconiza que “[...] é vedada a reutilização do mesmo animal depois de alcançado o objetivo principal do projeto de pesquisa” (BRASIL, 2008). Cabe ressaltar que a União Europeia está revisando a Diretiva que trata do uso científico de animais, em que a questão da reutilização também está sendo debatida, discutindo-se a possibilidade de se reutilizar ou não os animais em função da classificação geral do experimento, se leve, moderado ou substancial (EMBO, 2005; EUROHORCs, 2009; EUROPABIO, 2010).

Recente levantamento mostrou que cerca de $60 \%$ dos trabalhos científicos publicados se referem a modelos de redução, cabendo cerca de $30 \%$ aos métodos 
de substituição e 10\% visando o refinamento (REINHARDT, 2008). Esses números refletem de forma significativa a dificuldade atual de se encontrarem alternativas que substituam o uso de animais nas diversas áreas da experimentação e demonstram a importância da questão de redução do número de animais dentro do conceito dos três Rs. Talvez, o motivo principal da dificuldade de se estabelecer alternativas de substituição resida na necessidade de uma validação formal dos métodos, de forma a demonstrar a sua confiabilidade e relevância para o propósito particular (OECD, 2005; PRESGRAVE, 2009b).

O teste de pirogênio não oferece grandes problemas quando o resultado é negativo, entretanto, quando ocorre a resposta pirogênica, o animal pode sofrer algum desconforto em decorrência da elevação da temperatura, à semelhança do que acontece com seres humanos. Dessa forma, até que os Testes de Ativação de Monócitos possam substituir o uso de coelhos completamente, os estudos sobre a reutilização desses animais na determinação da contaminação pirogênica de produtos biológicos contribui sobremaneira para a redução do número de animais utilizados, uma vez que, no caso desse tipo de produto, os animais são usados uma única vez e submetidos à eutanásia.

Em face do acima exposto, ficam claras as vantagens dos métodos in vitro em relação ao in vivo, principalmente do MAT, que deve ser o método de escolha para a futura substituição do teste em coelhos e do LAL. Além disso, é necessário ressaltar a importância da utilização do MAT com sangue criopreservado na segurança e agilidade das análises. Entretanto, até que isso seja possível devido à necessidade de mais estudos, principalmente que correlacionem os resultados in vivo e in vitro, a redução do número de animais por meio da reutilização é uma alternativa segura e pode ser aplicada em curto prazo no controle da qualidade de produtos injetáveis.

\section{Conclusão}

Apesar de ainda ser amplamente utilizado, principalmente em países em desenvolvimento, o teste de pirogênio em coelhos tende a ser substituído por novas 
metodologias que quantificam a liberação de mediadores inflamatórios envolvidos no processo da febre. Com isso, a tendência mundial de substituir os animais fica bastante evidente.

O uso de métodos alternativos reduz de forma significativa os custos dos ensaios, quando comparado com os gastos necessários para a manutenção de animais de laboratório, podendo representar uma diminuição de até $70 \%$ do valor do teste in vivo. Dessa forma, o uso de um método alternativo como o MAT pode facilitar para que mais laboratórios possam executar o teste de pirogênio, aumentando a capacidade analítica da Rede Nacional de Laboratórios Oficiais de Controle de Qualidade em Saúde (RNLOCQS), proporcionando uma maior ação por parte da Vigilância Sanitária.

Os recentes estudos de validação e a incorporação do MAT na Farmacopeia Europeia mostram que o teste de pirogênio em coelhos pode, em um futuro próximo, ser completamente substituído, tanto para fins regulatórios quanto pelas indústrias. Entretanto, cabe ressaltar, até que esse método possa ser validado e incorporado à Farmacopéia Brasileira, o teste in vivo continua ser o de escolha, principalmente para produtos biológicos na detecção de substâncias pirogênicas. Nesse aspecto, a reutilização é uma alternativa importante na redução do número de animais e, portanto, deve ser implementada em curto prazo pelo menos nos produtos já estudados.

A utilização do MAT apenas para as treze drogas usadas no estudo colaborativo reforça a necessidade de novos processos de validação visando contemplar produtos de importância nacional como os imunobiológicos. Também é imprescindível que sejam incluídos nos processos de validação de cada produto, a comparação com os resultados obtidos no teste in vivo e no LAL, de forma que possam servir de base para o reconhecimento do MAT pelas Farmacopeias como um substituto completo dos métodos atualmente existentes. 


\section{Use of alternative methods for determining pyrogenic contamination in the control of injectable products subject to sanitary surveillance}

\section{Abstract}

All injected product for human use must be pyrogen-free. This contamination is considered a serious problem for public health, since they may cause fever and lead patients to shock or even, death. Pyrogen test is performed in rabbits, mainly for controlling hyperimmune sera, although LAL and MAT have being considered as alternatives for certain products. The aim of this study is to make a review about the evolution of pyrogen test and evaluate the possible regulatory acceptance of alternative methods by official laboratories in the control of injectable products. We concluded that, despite of the existence of alternatives, the lack of new studies and the limitation of the application of these methods, mainly for biological, it does not allow the replacement of the in vivo test unless in cases recommended by Pharmacopoeia. This way, despite of the ethical problems and the high cost of the use of animals, the assay using rabbits continues to be the choice to guarantee the quality of great part of the injectable products up to now, until that MAT can be validated and recognized for a wide class of products.

Keywords: Pyrogen. Alternative methods. Cytokine release. Pharmacopoeia.

\section{Referências}

ANDRADE, S. et al. Comparative evaluation of the human whole blood and human peripheral blood monocyte tests for pyrogens. International Journal of Pharmaceutics, v. 265, p. 115-124, 2003. doi:10.1016/j.ijpharm.2003.07.005.

BALLS, M.; BLAAUBOER, B. J.; FENTEM, J. H. Practical aspects of the validation of toxicity test procedures. ATLA, v. 23, p. 129-147, 1995.

BERNASCONI, C. et al. Pyrogenic activity of air to characterize bioaerosol exposure in public buildings: a pilot study. Letters in applied microbiology, v. 50, n. 6, p. 571-577, 2010. doi:10.1111/j.1472-765X.2010.02831.x

BEUTLER, B. LPS in microbial pathogenesis: promise and fulfilment. Journal of Endotoxin Research, v. 8, n. 5, p. 329-335, 2002. doi:10.1177/09680519020080050601. 
BLATTEIS, C. M.; SEHIC, E.; SHUXIN, L. Pyrogen sensing and signaling: old views and new concepts. Clinical Infectious Diseases, v. 31, p. 168-177, 2000. doi:10.1086/317522.

BOURG, V. et al. Estudio sobre la reutilización de los conejos utilizados para probar productos biológicos en el ensayo de pirógenos. Una alternativa para la reducción de animales. TALLER DE ENSAYOS BIOLÓGICOS, 1., La Habana, 1997. Anais..., La Hana: BioCien, 1997.

BRANDENBURG, K. et al., The expression of endotoxic activity in the Limulus test as compared to cytokine production in immune cells. Current Medicinal Chemistry, v. 16, n. 21, p. 2653-260, 2009. doi:10.2174/092986709788682001.

BRASIL. Decreto no 79.094, 05 de janeiro de 1977. Regulamenta a Lei no 6.360 de 23 de janeiro de 1976, que submete ao Sistema de Vigilância Sanitária, os medicamentos, insumos farmacêuticos, drogas correlatas, cosméticos, produtos de higiene, saneantes e outros. Diário Oficial [da] República Federativa do Brasil, Brasília, 05 jan. 1977.

BRASIL. Lei no 11.794, de 08 de outubro de 2008. Regulamenta o inciso VII de parágrafo $1^{\circ}$ do art. 225 da Constituição Federal, estabelecendo procedimentos para o uso científico de animais; revoga a Lei n. 6.638, de 8 de maio de 1979; e dá outras providências. Diário Oficial [da] República Federativa do Brasil, Brasília, 09 out. 2008.

BRASIL. Portaria no 500, de 09 de outubro de 1997. Aprova o regulamento técnico de soluções parenterais de grande volume - SPGV e seus anexos. Diário Oficial [da] República Federativa do Brasil, Brasília, 13 out. 1997. Seção 1, p. 2299623027.

BRASIL. Portaria SVS n. 109, de 4 de novembro de 1993. Delega ao INCQS a responsabilidade sobre emissão de parecer técnico sobre solicitação de registro e de programar as inspeções sobre Boas Práticas de Fabricação. Diário Oficial [da] República Federativa do Brasil, Brasília, 08 nov. 1993, p. 16.723, 1993.

BRASIL. Resolução RDC no 46, de 18 de maio de 2000. Aprova o regulamento técnico para a produção e controle de qualidade de hemoderivados de uso humano. Diário Oficial [da] República Federativa do Brasil, Brasília, 19 maio 2000. Seção 1, p. 41-47.

BROOM, M. Physiology of fever. Paediatric Nursing, v. 19, n. 6, p. 40-44, 2007. 
CALDEIRA, C. et al. The use of Mono Mac 6 cells as indicators of endotoxin contamination in the quality control of injectable products. Abstracts of the $7^{\text {th }}$ World Congress on Alternatives \& Animal Use in the Life Sciences; Berlin, Germany. ALTEX, v. 22, p. 213, 2005. Special Issue.

CHEN, J. et al. Comparative in vitro stimulation with lipopolysaccharide to study TNF alpha gene expression in fresh whole blood, fresh and frozen peripheral blood mononuclear cells. Journal Immunological Methods, v. 357, n. 1/2, p. 33-37.

DANESHIAN, M. Development, purpose and importance of in vitro pyrogenicity tests. Abstracts of the $7^{\text {th }}$ World Congress on Alternatives \& Animal Use in the Life Sciences; Aug 30-Sep03; Rome, Italy. ALTEX, v. 26, p. 22, 2009. Special Issue.

EMBO. Revision of the EC directive on the welfare of research animals: an advance briefing. Updated version, Dec. 2005. Disponível em: <www.embo.org >. Acesso em: 04 abr. 2010.

EPERON, S. et al. Human monocytoid cell lines as indicator of endotoxin: comparison with rabbit pyrogen and Limulus amoebocyte lysate assay. Journal of Immunological Methods, v. 2, n. 207, p. 135-145, 1997. doi:10.1016/S00221759(97)00112-9.

EPERON, S.; JUNGI, T. W. The use of human monocytoid lines as indicators of endotoxin. Journal of Immunological Methods, v. 194, n. 2, p. 121-129, 1996. doi:10.1016/0022-1759(96)00073-7.

EUROHORCs. European directive $86 / 809$ on the protection of animals used in scientific procedures: Extended summary of the opinions of the members of EUROHORCs on the main areas of concern on the revised draft of the directive. Jun. 2009. Disponível em: <http://www.eurohorcs.org/SiteCollectionDocuments/ EU_animals_Directive_revision_0904.pdf>. Acesso em: 04 abr. 2010.

EUROPABIO. Review of Directive 86/809 on the protection of animals used in scientific purposes. Disponivel em: <www.europabio.org.>. Acesso em: 15 fev. 2010 .

EUROPEAN PHARMACOPEIA. Monocyte activation test. General Method. Chapter 2.6.30. 6. ed. Strasbourg: EDQM, 2006.

FARMACOPEIA BRASILEIRA. 4. ed. São Paulo: Atheneu, 2003. Parte 2. Fascículo 5. 
FREITAS, J. C. B. R. A reutilização de coelhos submetidos ao teste de pirogênio com produtos biológicos sujeitos à vigilância sanitária. 2008. Dissertação (Mestrado)-Instituto Nacional de Controle de Qualidade em Saúde/FIOCRUZ, Rio de Janeiro, 2008.

FUKUMORI, N. T. O. Determinação de endotoxina bacteriana (pirogênio) em radiofármacos pelo método de formação de gel: validação. 2008. Dissertação (Mestrado)-Instituto de Pesquisas Energéticas e Nucleares. Universidade de São Paulo, São Paulo, 2008.

HALDER, M. In vitro pyrogenicity tests: lessons learned from the European validation study and ESAC peer review. Abstracts of the $7^{\text {th }}$ World Congress on Alternatives \& Animal Use in the Life Sciences; Aug 30-Sep03, Rome, Italy. ALTEX, v. 26, p. 22, 2009. Special Issue.

HANSEN, E. W.; CHRISTENSEN, J. D. Comparison of cultured human mononuclear cells, Limulus amebocyte lysate and rabbits in the detection of pyrogens. Journal of Clinical Pharmacy and Therapeutics, v. 15, n. 6, p. 425-33, 1990. doi:10.1111/j.1365-2710.1990.tb00407.x

HARTUNG, T. et al. Novel pyrogen tests based on the human fever reaction. ATLA, v. 29, p. 99-123, 2001.

HARTUNG, T.; WENDEL, $A$. Detection of pyrogens using human whole blood. In vitro Toxicology, v. 9, n.4, p. 353-359, 1996.

HARTUNG, T.; WENDEL, A. Die erfasung von pyrogenen in einem humanen vollblutmodell. ALTEX, v. 12, n. 2, p. 70-75, 1995.

HOCHSTEIN, H. D.; MUNSON, T. E.; OUTSCHOORN, A. S. Comparison of rabbit responses of two E. coli endotoxin preparations in the USP rabbit pyrogen test. Pharmacopeial Fórum, p. 346-351, mar./abr. 1990.

HOFFMANN, S. et al. Optimization of testing in parenterals according to different pharmacopoeias by probabilistic modeling. Journal of Endotoxin Research, v. 11, p. 25-31, 2005a. doi: 10.1177/09680519050110010701.

HOFFMANN, S. et al. International validation of novel pyrogen tests based on human monocytoid cells. Journal of Immunological Methods, v. 298, p. 161-173, 2005b. doi:10.1016/j.jim.2005.01.010. 
HUSZÁR, G. et al. Detection of Pyrogens in Intravenous IgG Preparations. Biologicals, v. 30, p. 77-83, 2002. doi:10.1006/biol.2001.0311.

ICCVAM. Validation status of five in vitro test methodsd proposed for assessing potential pyrogenicity of pharmaceuticals and other products: ICCVAM test method evaluation report. NIH, n. 8, p. 6392, 2008.

INCQS. Atividades institucionais. Rio de Janeiro: Fiocruz, 2005.

KINDINGER I. et al. A new method to measure air-borne pyrogens based on human whole blood cytokine response. Journal of Immunological Methods, v. 298, n. 1-2, p. 143-153, mar. 2005. doi:10.1016/j.jim.2005.01.006.

MOESBY, L. et al. A comparative study of Mono Mac 6 cells, isolated mononuclear cells and Limulus amoebocyte lysate assay in pyrogen testing. International Journal of Pharmacy, v. 191, n. 2, p. 141-149, 1990. doi:10.1016/S0378-5173(99)00294-X.

MONTAG, T. et al The monocyte activation test (MAT) for pyrogens in year zero of its regulatory acceptance. Abstracts of the $7^{\text {th }}$ World Congress on Alternatives \& Animal Use in the Life Sciences; Aug 30-Sep03, Rome, Italy. ALTEX, v. 26, p. 23, 2009. Special Issue.

NAKAGAWA, Y; MAEDA, H.; MURAI, T. Evaluation of the in vitro pyrogen test system based on proinflammatory cytokine release from human monocytes: Comparison with a human whole blood culture test system and with the rabbit pyrogen test. Clinical and Diagnostic Laboratory Immunology, v. 9, n. 3, p. 588$597,2002$.

NETEA, M. G.; KUllbERG, B. J.; VAN DER MEER, J. W. M. Circulating cytokines as mediators of fever. Clinical Infectious Diseases, v. 31, p. 178-184, 2000. doi:10.1086/317513.

OECD. Guidance Document on the Validation and International Acceptance of New or Updated Test Methods for Hazard Assessment. OECD Series on Testing and Assessment, Number 34. ENV/JM/MONO. Organisation for Economic Cooperation and Development, Paris, v. 14, p. 96, 2005.

PARK, C.Y. et al. Comparison of the rabbit pyrogen test and Limulus amoebocyte lysate (LAL) assay for endotoxin in hepatitis $B$ vaccines and the effect of aluminum hydroxide. Biologicals, v.33, p. 145-151, 2005. doi:10.1016/j. biologicals.2005.04.002. 
PINTO, T. J. A.; KANEKO, T. M.; OHARA, M. T. Controle biológico de qualidade de produtos farmacêuticos, correlatos e cosméticos. 2. ed. São Paulo: Atheneu, 2003.

POOLE, S. et al. A rapid 'one-plate' in vitro test for pyrogens. Journal of Immunological Methods, v. 274, n. 1-2, p. 209-220, 2003. doi:10.1016/S00221759(02)00519-7.

POOLE, S. et al., Detection of pyrogen by cytokine release. Lancet, v. 8577, p. 130, 1988. doi:10.1016/S0140-6736(88)90338-8

PRESGRAVE, O. A. F. et al. The use of cryopreserved whole blood for detecting pyrogenic contamination of injectable products. Brazilian Journal of Toxicology, v. 20, p. 77, 2007.

PRESGRAVE, O. A. F. et al. The use of cytokine release (whole blood assay) for detecting pyrogens in anti-venom sera. Abstracts of the $7^{\text {th }}$ World Congress on Alternatives \& Animal Use in the Life Sciences; 2009 Aug 21-25; Berlin, Germany. ALTEX, v. 22, p. 221, 2009a. Special Issue.

PRESGRAVE, O. A. F. Liberação de citocinas como método alternativo ao ensaio de pirogênio em coelhos no controle de qualidade de produtos injetáveis. 2003. Dissertação (Mestrado)-Fiocruz, Rio de Janeiro, 2003.

PRESGRAVE, O. A. F. Métodos alternativos. In: LAPCHIK V. B. V.; MATTARAIA V. G. M; KO G. M. (Ed.). Cuidados e manejo de animais de laboratório. São Paulo: Atheneu, 2009b.

REINHARDT, V. Taking better care of monkeys and apes. Washington: Animal Welfare Institute, 2008.

RUSSEL, W. M. S.; BURCH, R. L. The principles of humane experimental technique. Londres: Methuen, 1959.

SCHINDLER, S. et al. Cryopreservation of human whole blood por pyrogenicity testing. Journal of Immunological Methods, v. 294, p. 89-100, 2004. doi:10.1016/j. jim.2004.08.019.

SCHINDLER, S. et al. Development, validation and applcations of the monocyte activation test for pyrogens based on human whole blood. ALTEX, [S.l.], v. 26, p. 265-277, 2009. 
SCHINDLER, S. et al. International validation of pyrogen tests based on cryopreserved human primary blood cells. Journal of Immunological Methods, v. 316, p. 42-51, 2006. doi:10.1016/j.jim.2006.07.023

SILVA, C. et al Cryopreserved whole blood cytokine release assay for determining endotoxin contamination of hyperimmune sera. Abstracts of the $7^{\text {th }}$ World Congress on Alternatives \& Animal Use in the Life Sciences; Aug 30-Sep 03, Rome, Italy. ALTEX, v. 26, p. 212, 2009. Special Issue.

SILVEIRA, R. L. et al. Comparative evaluation of pyrogens tests in pharmaceutical products. Journal of Microbiology, v. 35, p. 48-53, 2004.

SIQUEIRA, J. F.; DANTAS, C. J. S. Mecanismos celulares e moleculares da inflamação. Rio de Janeiro: Medsi, 2000.

SPREITZER, I. et al. Comparative study of rabbit pyrogen test and human whole blood assay on human serum albumin. ALTEX, n. 19, p. 73-75, 2002. Supplement 1.

STODDARD, M. B. et al. Evaluation of a whole-blood cytokine release assay for use in measuring endotoxin activity of group B Neisseria meningitidis vaccines made from lipid A acylation mutants. Clinical Vaccine Immunology, v. 17, n. 1, p. 98-107, 2010. doi:10.1128/CVI.00342-09.

TAKTAK, Y. S. et al. Assay of pyrogens by interleukin-6 release from monocytic cell lines. Journal of Pharmacy and Pharmacology, n. 43, p. 578-582, 1991.

UNITED STATES PHARMACOPEIA. Maryland: USP, 2000.

WILLIAMS, L.K. Endotoxins. Pirogens, LAL testing and depyrogenation. 2. ed. New York: Marcel Dekker, 2007.

ZIEGLER-HEITBROCK, H.W. et al. Establishment of a human cell line (Mono Mac 6) with characteristics of mature monocytes. International Journal of Cancer, v. 41, n. 3, p. 456-61, 1988. doi:10.1002/ijc.2910410324. 
Para publicar na revista Universitas: Ciências da Saúde, acesse o endereço eletrônico www.publicacoesacademicas.uniceub.br. Observe as normas de publicação, para facilitar e agilizar o trabalho de edição. 